\title{
Sensitivity of solar greenhouse envelopes to the thermal disfigurements and optimal selection of the thermal insulation quilt
}

\author{
Yachen Sun ${ }^{1,7^{* *}}$, Yao Zhang ${ }^{2,3^{\dagger}}$, Chenmeng Zhu ${ }^{4}$, Shaonan $\mathrm{Xu}^{5}$, Bowen $\mathrm{Liu}^{6}$, Yanfei Cao ${ }^{7}$, \\ Changji Zhou ${ }^{8}$, Yaqi Zhou', Zhirong Zou', Encai Bao ${ }^{2 *}$ \\ (1. College of Architecture and Urban Planning, Tongji University, Shanghai 200092, China; \\ 2. Institute of Agricultural Facilities and Equipment, Jiangsu Academy of Agricultural Science, Key Laboratory of Protected Agriculture \\ Engineering in the Middle and Lower Reaches of Yangtze River, Ministry of Agriculture and Rural Affairs, Nanjing 210014, China; \\ 3. School of Engineering, Anhui Agricultural University, Hefei 230036, China; \\ 4. Department of Management, City University of Hong Kong, Tat Chee Avenue Kowloon, Hong Kong 999077, China; \\ 5. Qinghai College of animal husbandry and veterinary technology, Xining 812100, China; \\ 6. School of Ocean and Earth Science, Tongji University, Shanghai 200092, China; \\ 7. Key Laboratory of Protected Horticultural Engineering in Northwest, Ministry of Agriculture and Rural Affairs, Department of \\ Horticulture, Northwest A\&F University, Yangling 712100, Shaanxi, China; \\ 8. Academy of Agricultural Planning and Engineering, Ministry of Agriculture and Rural Affairs, Beijing 100125, China; \\ 9. School of Karst Science, Guizhou Normal University, Guiyang 550001, China)
}

\begin{abstract}
The objectives of the present work are focused on exploration of the reasons for temperature difference in different envelopes, the sensitivity of envelopes of solar greenhouse to thermal disfigurements and optimal selection of the thermal insulation quilt. Theoretical analysis and derivation are conducted according to the experimental results of surface temperature, convective heat transfer, and heat flux density in different envelopes which with thermal disfigurements of solar greenhouse using heat transfer theory. The results revealed that the difference of intrinsic thermal conductivity and thickness of the envelopes leads to difference in the thermal flux and thus in the surface temperature of different envelopes. Compared with the front roof and back roof, the wall is more sensitive to thermal disfigurements. According to the influence of thermal disfigurements on solar greenhouse temperature, the allowable thermal disfigurements area fraction of front roof and back roof are given. Based on the analysis of heat transfer theory and test results, the work given the expression of the thickness and thermal conductivity of thermal insulation quilt under different outdoor minimum temperatures for optimal selection of thermal insulation quilt based on comprehensive considering factors of the solar greenhouse structure, crop demand, outdoor minimum temperature, and insulation quilt properties. The results of this work give technical criterion for whether the envelopes with thermal disfigurements needs to be repaired or replaced, and it also provides theoretical and technical support for design the solar greenhouse as well as methodological guidance for the optimal selection of the thermal insulation quilt.
\end{abstract}

Keywords: solar greenhouse, thermal disfigurements, optimal selection, thermal insulation quilt

DOI: $10.25165 /$ j.ijabe.20211405.6311

Citation: Sun Y C, Zhang Y, Zhu C M, Xu S N, Liu B W, Cao Y F, et al. Sensitivity of solar greenhouse envelopes to the thermal disfigurements and optimal selection of the thermal insulation quilt. Int J Agric \& Biol Eng, 2021; 14(5): 50-55.

\section{Introduction}

Thermal insulation is the most important measurements to reduce the heat loss of solar greenhouse. The existence of thermal disfigurements in envelopes will deteriorate the thermal insulation performance of solar greenhouse envelopes and thus be detrimental to keeping indoor temperature high enough at night. The previous work $^{[1]}$ showed that the temperature difference can be displayed in the thermal infrared images of compartment envelopes, the surface

Received date: 2020-11-27 Accepted date: 2021-11-27

Biographies: Yao Zhang, Master candidate, research interests: facility horticulture engineering, Email: 1520121762@qq.com; Chenmeng Zhu, Master candidate, research interests: organizational management, Email: cmzhu4-c@my.cityu.edu.hk; Shaonan Xu, Master, Lecturer Fellow, research interests: facility horticulture engineering, Email: 329788084@qq.com; Bowen Liu, $\mathrm{PhD}$, research interests: thermal drilling in antarctic, Email: 20087@tongji.edu.cn; Yanfei Cao, PhD, research interests: greenhouse structure optimization, Email: caoyanfei@nwsuaf.edu.cn; Changji Zhou, PhD, Researcher, research interests: facility horticulture, Email: zhoucj@ facaae.com; temperature of the front roof was the lowest, followed by the back roof, the wall surface temperature was the highest. And the existence of thermal disfigurements will lead to the increase of convective heat transfer coefficient and heat flux in the disfigurements area, while the temperature will decrease. Generally speaking, the larger the thermal disfigurements area, the more obvious the temperature drop. However, the reason for the difference in the surface temperature of different envelopes is not clear. And the knowledge about the influence degree of per area

\footnotetext{
Yaqi Zhou, PhD, Lecturer Fellow, research interests: ecological management of bamboo forest, Email: zhouyaqi_@126.com; Zhirong Zou, PhD, Professor, research interests: facility horticulture, Email: zouzhirong2005@163.com. $\uparrow$ These authors contribute equally to this research.

*Corresponding authors: Yachen Sun, $\mathrm{PhD}$, research interests: facility horticulture. Tel: +86-17602144021, Email: sunyachen1993@163.com; Encai Bao, $\mathrm{PhD}$, Assistant Research Fellow, research interests: facility horticulture engineering. Institute of Agricultural Facilities and Equipment, Jiangsu Academy of Agricultural Science, Nanjing 210014, China. Tel: +86-17768103527, Email baoencai1990@163.com.
} 
of thermal disfigurements on convective heat transfer coefficient and heat flux increase or temperature decrease of different envelopes is lacking. In particular, there is no answer to the maximum scale of thermal disfigurements in the envelopes that can be allowed to ensure the solar greenhouse works properly. Therefore, it is difficult to provide reasonable support for the assessment of the influence of thermal disfigurements on solar greenhouse performance and give technical criterion for whether the envelopes with thermal disfigurements needs to be repaired or replaced. On the other hand, though it is demonstrated that construction of brick wall at the bottom of south side of the front roof is helpful to increase the inner surface temperature of the front roof, its beneficial effect is partially and limited. Moreover, the wall constructed at the bottom of south side of the front roof will affect the indoor lighting which is unfavorable to crops growth. In practice, the thermal insulation of the front roof mainly depends on the performance of the thermal insulation quilt ${ }^{[2-5]}$. As a result it is necessary to explore the considerations on the selection of thermal insulation quilt to ensure the front roof insulation.

Lots of works have been conducted on the material, thickness and thermal insulation performance of the thermal insulation quilt sold on the market ${ }^{[2,6-8]}$. For example, Zhang ${ }^{[9]}$ summarized the quality evaluation indices of thermal insulation quilt including specification and size, strength, waterproof performance and thermal conductivity performance. And it is pointed that the tensile strength, waterproof and heat transfer coefficient are the most important parameters for quality evaluation of thermal insulation quilt. Research of Liu et al. ${ }^{[10]}$ pointed out that when the heat transfer coefficient of the thermal insulation quilt is large and the emissivity of its upper surface is small, the heat transfer coefficient of the quilt increases with the increase of the outdoor wind speed. When the heat transfer coefficient of the heat preservation quilt is small, the emissivity of the upper surface of the heat preservation quilt is larger, and the heat transfer coefficient of the heat preservation quilt decreases with the increase of the outdoor wind speed. The heat transfer coefficient of thermal insulation quilt decreased with thickness increasing or heat conductivity coefficient of thick cover materials reducing. Furthermore, the relationship between the heat transferred by means of convection and radiation was established ${ }^{[11]}$. And thus, the heat transfer flux density and heat transfer coefficient of quilt could be simulated and forecasted according to the infrared radiation characteristics, thermal conductivity, structural parameters and working environment of the quilt materials.

The above research provides a certain technical reference for the selection of thermal insulation quilt in solar greenhouse. However, the proportion of the front roof area of the solar greenhouse varied with the structure of greenhouse ${ }^{[12]}$, which will lead to heat loss through the front roof was different. Moreover, crop demand determines the lowest indoor temperature which can guarantee the growth of the crop. Consequently, for the selection of thermal insulation quilt, it is necessary to consider the factors of solar greenhouse structure and crops concerned besides outdoor environments factors and intrinsic parameters of thermal insulation quilt. Unfortunately, reports on the selection of thermal insulation quilt comprehensive considering the above factors are lacking.

Based on the experimental results of our earlier work about the influence of thermal disfigurement on the convective heat transfer of solar greenhouse, the present work mainly focused on exploring the reason for the difference in the surface temperature of different envelopes and analyzing the sensitivity of different envelopes of solar greenhouse to thermal disfigurements. After that the work tried to give the allowable scale of the thermal disfigurements in envelopes of the tested solar greenhouse. Finally, it deducted considerations on the selection of thermal insulation quilt including the factors of solar greenhouse structure and crops concerned besides outdoor environments factors and intrinsic parameters of thermal insulation quilt.

\section{Materials and methods}

The experiment was conducted in the No. 1 solar greenhouse in Northwest A\&F University, Yangling, China in December, 2018. The length of the solar greenhouse is $50.0 \mathrm{~m}$, and the net span is $8.0 \mathrm{~m}$. The north wall (back wall) height is $2.2 \mathrm{~m}$, with a thickness of $1.0 \mathrm{~m}$, and a $10 \mathrm{~cm}$ thick polystyrene board. The ridge height of the solar greenhouse is $3.5 \mathrm{~m}$. The thickness of east and west clay brick walls is $1.0 \mathrm{~m}$. The back slope is made of color steel bond-polystyrene with a thickness of $101 \mathrm{~mm}$ (the thickness of polystyrene board is $100 \mathrm{~mm}$ ) and width is $1.7 \mathrm{~m}$, respectively. The front roof is covered by thermal insulation quilt with a thickness of $3 \mathrm{~cm}$ and thermal conductivity of $0.03 \mathrm{~W} /(\mathrm{m} \cdot \mathrm{K})$ There is a $3.0 \mathrm{~m} \times 3.0 \mathrm{~m}$ auxiliary room in the east of the solar greenhouse. The greenhouse is divided in to 5 compartments with the color bond-polystyrene board as shown in Figure 1.

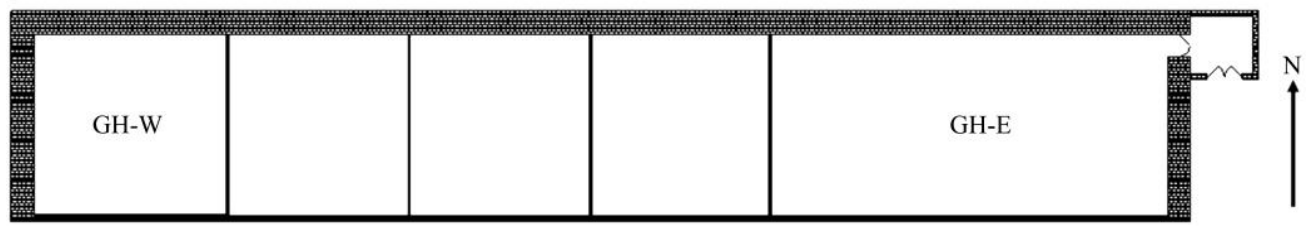

Figure 1 Plan view of experimental solar greenhouse

The west compartment (GH-E, the length is $16 \mathrm{~m}$ ) and east compartment (GH-W, the length is $8 \mathrm{~m}$ ) of solar greenhouse are chosen for thermal disfigurements study. Different thermal disfigurements are prefabricated for each envelope. For the front roof, considering the thermal insulation quilt may be partially damaged or thinned in practical use, this work takes the partial thinning of the thermal insulation quilt for the two selected compartments as the thermal disfigurements. The gap between the polystyrene board joints is set as the thermal disfigurements of the back roof. And local thinning of the back wall (the wall is set with holes with a depth of $240 \mathrm{~mm}$ ) and the entrance of the gable in the east compartment are regarded as thermal disfigurements of walls. Figure 2 shows the photos of thermal disfigurements such as the gap between polystyrene board on the back roof and the local thinning of the back wall. The other three compartments in the middle are free of the above thermal disfigurements.

The C2 thermal infrared imager produced by FLIR Ltd., America was used for detecting the surface temperature of envelops of the solar greenhouse. Data was collected on a cloudy day (Dec. 10, 2018) at 17:30-18:30, and the greenhouse was covered with thermal insulation quilt. Details of the experimental process are described in the previous work ${ }^{[1]}$. 


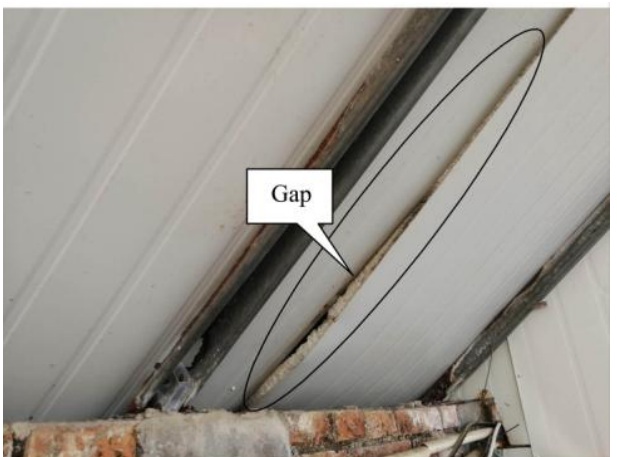

a. Gap between polystyrene board

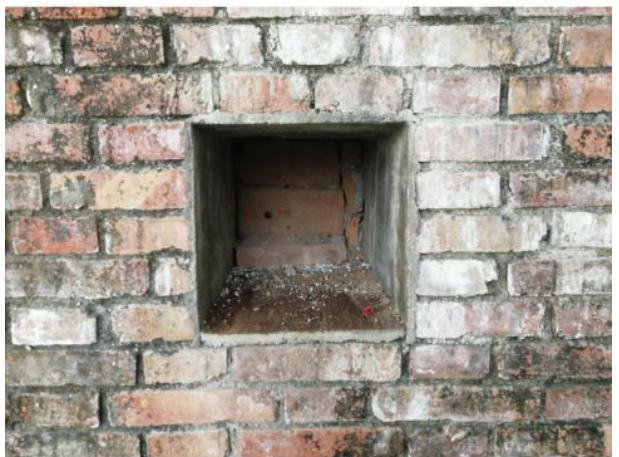

b. Local thinning of back wall

Figure 2 Photos of the prefabricated thermodynamic disfigurement (a) Gap between polystyrene board; (b) Local thinning of back wall

\section{Results and discussion}

\subsection{Sensitivity of envelopes of the solar greenhouse to thermal disfigurements}

Table 1 lists the test results of thermal disfigurements area fraction, average surface temperature, surface convective heat transfer coefficient, heat flux and calculated relative changes of them of different envelopes of the solar greenhouse.

Table 2 lists the normalized area of thermal disfigurements on convective heat transfer coefficient, heat flux and temperature of different areas in the solar greenhouse based on the tested results listed in Table 1. In general, the increment of convective heat transfer coefficient and heat flux of the wall with thermal disfigurements are significantly higher than those of the front roof and back roof, the same to the decrement of surface temperature. This suggests when the area fraction of thermal disfigurements is the same, the change of thermal performance of the wall is the most obvious, i.e. the wall is more sensitive to thermal disfigurements.

Table 1 Area fraction of thermal disfigurement, convective heat transfer coefficient, heat flux density, surface temperature and their relative change of different regions in the solar greenhouse

\begin{tabular}{|c|c|c|c|c|c|c|c|c|c|c|c|}
\hline \multirow[b]{2}{*}{ Compartment } & \multirow[b]{2}{*}{ Envelope } & \multicolumn{4}{|c|}{ Thermal disfigurements } & \multicolumn{3}{|c|}{ Non-thermal disfigurements } & \multicolumn{3}{|c|}{ Relative changes $/ \%$} \\
\hline & & $\begin{array}{c}\text { Average } \\
\text { temperature } \\
/^{\circ} \mathrm{C}\end{array}$ & $\begin{array}{c}\text { Area fraction of } \\
\text { thermal } \\
\text { disfigurement } / \%\end{array}$ & $\begin{array}{c}\text { Average } \\
\text { convective heat } \\
\text { transfer } \\
\text { coefficient } \\
/ \mathrm{W} \cdot\left(\mathrm{m}^{2} \cdot{ }^{\circ} \mathrm{C}\right)^{-1}\end{array}$ & $\begin{array}{c}\text { Average } \\
\text { heat flux } \\
/ \mathrm{W} \cdot \mathrm{m}^{-2}\end{array}$ & $\begin{array}{c}\text { Average } \\
\text { temperature } \\
{ }^{\circ} \mathrm{C}\end{array}$ & $\begin{array}{c}\text { Average } \\
\text { convective heat } \\
\text { transfer } \\
\text { coefficient } \\
/ \mathrm{W} \cdot\left(\mathrm{m}^{2} \cdot{ }^{\circ} \mathrm{C}\right)^{-1}\end{array}$ & $\begin{array}{c}\text { Average } \\
\text { heat flux } \\
/ \mathrm{W} \cdot \mathrm{m}^{-2}\end{array}$ & $\begin{array}{c}\text { Average } \\
\text { temperature }\end{array}$ & $\begin{array}{c}\text { Average } \\
\text { convective } \\
\text { heat transfer } \\
\text { coefficient }\end{array}$ & $\begin{array}{c}\text { Average } \\
\text { heat flux } \\
\text { density }\end{array}$ \\
\hline \multirow{2}{*}{ GH-E } & Front roof & 5.4 & 16.5 & 4.27 & 31.35 & 8.5 & 3.55 & 14.90 & -36.47 & +20.28 & +110.40 \\
\hline & Wall & 9.8 & 4.8 & 2.66 & 7.84 & 13.0 & 1.25 & 0.38 & -24.62 & +112.8 & +1963.16 \\
\hline \multirow{3}{*}{ GH-W } & Front roof & 10.0 & 2.6 & 4.04 & 25.02 & 11.1 & 3.78 & 19.30 & -9.91 & +6.88 & +29.64 \\
\hline & Back roof & 12.6 & 3.4 & 2.84 & 10.22 & 13.9 & 2.45 & 5.63 & -9.35 & +15.92 & +81.52 \\
\hline & Wall & 13.5 & 1.3 & 2.58 & 6.97 & 15.0 & 1.98 & 2.37 & -10.00 & +30.30 & +194.09 \\
\hline
\end{tabular}

Table 2 Effects of the normalized area of thermal disfigurements on convective heat transfer coefficient, heat flux and temperature of different areas in the solar greenhouse

\begin{tabular}{ccccc}
\hline \multirow{2}{*}{$\begin{array}{c}\text { Compartment of } \\
\text { greenhouse }\end{array}$} & Region & $\begin{array}{c}\text { Relative changes /\% } \\
\text { Aveat transfer coefficient }\end{array}$ & $\begin{array}{c}\text { Average heat } \\
\text { flux density }\end{array}$ & $\begin{array}{c}\text { Average } \\
\text { temperature }\end{array}$ \\
\hline \multirow{2}{*}{ GH-E } & Front roof & +1.23 & +6.69 & -2.21 \\
& Back roof & -- & -- & -- \\
& Wall & +23.50 & +408.99 & -5.13 \\
\hline \multirow{2}{*}{ GH-W } & Front roof & +2.65 & +11.40 & -3.81 \\
& Back roof & +4.68 & +23.98 & -2.75 \\
& Wall & +23.31 & +149.30 & -7.69 \\
\hline
\end{tabular}

In the present work, the solar greenhouse is the same and the temperature difference between the east and west compartment is small $\left(3.5^{\circ} \mathrm{C}\right)$. The thermal conductivity of solids is usually linear with temperature. Thus, it can be considered that the thermal conductivity of each envelops which are free of thermal disfigurements in the east and west compartment of the solar greenhouse is basically the same. According to Fourier's law, the heat flux through solid, $q$ can be expressed as ${ }^{[13,14]}$.

$$
q=-\lambda \frac{\partial T}{\partial x}=\lambda \frac{\Delta T}{\delta}
$$

where, $q$ is the heat flux through solid, $\mathrm{W} / \mathrm{m}^{2} ; \lambda$ is the thermal conductivity, $\mathrm{W} /(\mathrm{m} \cdot \mathrm{K}) ; \delta$ is the thickness of solid, $\mathrm{mm} ; \Delta T$ is the temperature difference between the two sides of the solid, K.

In the present work, the thickness and thermal conductivity of the wall are $1 \mathrm{~m}$ and $0.58 \mathrm{~W} /(\mathrm{m} \cdot \mathrm{K})$, respectively. The thickness and thermal conductivity of the back roof are $0.101 \mathrm{~m}$ and $0.08 \mathrm{~W} /(\mathrm{m} \cdot \mathrm{K})$, respectively. The thickness and thermal conductivity are $\delta_{\text {quilt }}=0.03 \mathrm{~m}$ and $\lambda_{\text {quilt }}=0.03 \mathrm{~W} /(\mathrm{m} \cdot \mathrm{K})$ for the thermal insulation quilt, and $\delta_{P O}=0.0001 \mathrm{~m}$ and $\lambda_{P O}=0.03 \mathrm{~W} /(\mathrm{m} \cdot \mathrm{K})$ for the PO film, respectively. According to Equation (1), the thermal flux through the wall $q_{w}$ and back roof $q_{b r}$ can be described as $q_{w}=0.58 \Delta T$ and $q_{b r}=0.8 \Delta T$, respectively. While the thermal flux through the front roof $q_{f r}$ can be described as ${ }^{[15,16]}$ :

$$
q_{f r} \frac{\Delta T}{\frac{\delta_{P O}}{\lambda_{P O}}+\frac{\delta_{\text {quilt }}}{\lambda_{\text {quilt }}}} \approx \Delta T
$$

Therefore, when the indoor temperature is the same and there are no thermal disfigurements, the heat flux through every kind of envelope is different. And heat flux through the front roof is the highest, while that through the back wall is the lowest, indicating the front roof is the main channel of indoor heat loss.

The surface emitted heat conduction $\lambda_{r}$ from solid to environment by radiation can be expressed as follows ${ }^{[17]}$. 


$$
\lambda_{r}=\frac{16}{3} n^{2} \sigma T^{3} l_{r}
$$

where, $\lambda_{r}$ is surface emitted heat conductivity from solid to environment by radiation, $\mathrm{W} /(\mathrm{m} \cdot \mathrm{K}) ; n$ is refractive coefficient; $\sigma$ is Stephen Boltzmann's constant, $5.67 \times 10^{-8} \mathrm{~W} /\left(\mathrm{m}^{2} \cdot \mathrm{K}^{4}\right) ; T$ is the surface temperature of solid, $\mathrm{K} ; l_{r}$ is mean free path of photons, $\mathrm{m}$.

As the surface temperature of envelops of the west compartment is higher than that of the east compartment. Therefore, according to Equation (3), the surface emitted heat conduction of each envelope to outdoor by radiation in the west compartment is greater than that in the east compartment. Moreover, the indoor temperature of the west compartment is higher than that of the east compartment. Therefore, according to Equation (1), the heat flux through envelopes in the west compartment is higher than that in the east compartment. As a result, in the case of the area fraction of thermal disfigurements in every kind of envelope is the same, the change of convective heat transfer coefficient, average heat flux and indoor temperature of the west compartment will be more obvious than those of the east compartment. The above analysis and discussion also indicate the difference of intrinsic thermal conductivity and thickness of the envelopes leads to a difference in the thermal flux.

When there are penetrated thermal disfigurements, such as the entrance on the wall and the rupture of the thermal insulation quilt, the thickness of the disfigurements area will become 0 . According to Equations (1) and (2), the heat flux at such penetrated thermal disfigurements will tend to infinity, that is to say, it will lead to rapid and dramatic heat conduction. As a result, the temperature around penetrated thermal disfigurements would be obvious lower as demonstrated that there are abnormal increment of convective heat transfer coefficient and average heat flux through the wall in the east compartment due to there is an entrance in the wall. When there are non-penetrated thermal disfigurements, such as the area of local thinning of wall or thermal insulation quilt, the thermal flux through such non-penetrated thermal disfigurements area will increase significantly. It is conceivable that the larger the thermal disfigurements area, the greater the corresponding thermal flux and convective heat transfer coefficient increment.

On the other hand, it should be noted that for the front roof, in most case, PO film should be free of rupture, only the thermal insulation quilt may have penetrated rupture. According to Equation (2), the thermal flux through the front roof around the penetrated rupture would be limited to sharp increase due to the PO film is free of thermal disfigurements. As a result, when there are penetrated thermal disfigurements and the area is the same, the increment of thermal flux around penetrated thermal disfigurements through front roof should be lower than that through the wall as shown in Table 1 for both the east and west compartment. As the thermal conductivity of the back roof is significantly smaller than that of the wall, the relative increment of thermal flux around penetrated thermal disfigurements through back roof should be lower than that through the wall as shown in Table 1 for the west compartment.

As a result, according to the above results and discussion, it can be concluded that the wall is the most sensitive envelope to thermal disfigurements than the back roof and the front roof.

It should be noted that the above results and conclusions are based on there is thermal insulation quilt on the front roof. If there is no thermal insulation quilt, the front roof, i.e. merely PO film should be the most sensitive envelope to thermal disfigurements due to its thickness is significantly smaller than that of the back roof and the wall.

\subsection{Allowable scale of the thermal disfigurements in envelopes of greenhouse}

According to the above results and analysis, it can be concluded that the envelopes directly affect the indoor temperature of solar greenhouse. Thermal disfigurements in envelopes make the thermal flux through the relevant envelopes increased and thus increased the indoor temperature drop. Consequently, in order to ensure that the indoor temperature drop is within the allowable range, it is necessary to limit the scale of thermal disfigurements.

Assuming the influence of thermal disfigurements in envelopes on the temperature is proportional to its area fraction under the condition that the solar greenhouse can work normally. Supposing the area fraction of thermal disfigurements in envelopes is $\varepsilon$, the influence of normalized per area thermal disfigurements on temperature is $\beta$, the surface temperature of the envelope without thermal disfigurements is $T_{f}$, and the temperature of the envelope with thermal disfigurements is $T_{d}$. Thus the relationship of $\varepsilon, \beta, T_{f}$ and $T_{d}$ can be expressed as:

$$
\begin{gathered}
T_{d}=T_{f}(1+\beta \varepsilon) \\
\varepsilon=-\frac{1}{\beta}\left(1-\frac{T_{d}}{T_{f}}\right)
\end{gathered}
$$

According to the tested results listed in Table 1, the temperature of middle compartment which can be considered as free of thermal disfigurements in envelopes is $T_{f}=12.316^{\circ} \mathrm{C}$. According to the results listed in Table 2, the value of $\beta$ for both the west and east compartments with thermal disfigurements in front roof, is $\beta_{f r w}=-3.81 \%$ and $\beta_{f r e}=-2.21 \%$, respectively. Setting aside the influence of thermal disfigurements in the other two envelopes, and the average surface temperature of front roof of the west compartment is $T_{d w}=11.1^{\circ} \mathrm{C}$ and that of east compartment is $T_{d e}=8.5^{\circ} \mathrm{C}$, respectively. According to Equation (5), it can be calculated that the area fraction of thermal disfigurements in front roof of the west compartment is $\varepsilon_{f r w}=2.59 \%$ and that of the east compartment is $\varepsilon_{f r e}=14.02 \%$, respectively. These estimated results are very close to that of the tested results $\varepsilon_{f r w}=2.60 \%$ and $\varepsilon_{f r e}=16.5 \%$ as listed in Table 1, indicating Equation (5) can be applied to evaluate the allowable size of thermal disfigurements in envelopes.

Assuming the allowable lowest indoor temperature is $8^{\circ} \mathrm{C}$. According to Equation (5), it can be calculated the allowable area fraction of thermal disfigurements in front roof of the west and east compartment is $\varepsilon_{f r w \max }=9.20 \%$ and $\varepsilon_{f r e \max }=15.86 \%$ for the present concerned solar greenhouse, respectively.

Similarly, it can be estimated that when only the back roof has thermal disfigurements, the allowable area fraction of thermal disfigurements in front roof of the west compartment is $\varepsilon_{b r w \max }=17.05 \%$.

For the wall, due to the thermal disfigurements is mainly thickness thinning. However, due to the large thickness of the wall, the extent of thickness reduction varies greatly. And thus, the influence of normalized per area thickness thinning in wall on temperature $\beta$ is difficult to quantitative determine. Evaluation of the allowable area fraction of thermal disfigurements in wall is not conducted.

\subsection{Considerations on selection of thermal insulation quilt}

According to the above results and analysis, when there are no thermal disfigurements in envelopes, the heat loss of solar greenhouse is mainly through front roof. Therefore, intensive 
attentions should be paid to improving the insulation of the front roof. The adopted PO film for given solar greenhouse is usually fixed, namely the thermal conductivity and thickness of it keep the same. Therefore, considerations on the selection of thermal insulation quilt are particularly important.

To simplify the analysis, assuming that the temperature of the front roof on the indoor side is always equal to the average indoor temperature and the outdoor temperature, $T_{o}$ keeps constant. When front roof is covered by the thermal insulation quilt, the average indoor temperature is $T_{h}$ while the final average lowest indoor temperature is $T_{l}$. The heat transferred through the envelopes $Q_{d}$ should be equal to the released heat of the indoor air $Q_{a}$ caused by indoor air temperature drop. According to Equation (1), the heat transferred through the front roof $Q_{d f r}$ during the period from thermal insulation quilt closing to the next opening, $t$ can be described as:

$$
Q_{d f r}=q_{f r} A_{f r} t=\frac{\Delta T}{\frac{\delta_{P O}}{\lambda_{P O}}+\frac{\delta_{\text {quilt }}}{\lambda_{\text {quilt }}}} A_{f r} t=\frac{T_{h}-T_{O}}{\frac{\delta_{P O}}{\lambda_{P O}}+\frac{\delta_{\text {quilt }}}{\lambda_{\text {quilt }}}} A_{f r} t
$$

As the heat transferred through the front roof $Q_{d f r}$ accounts for $70 \%-80 \%$ of the total heat loss of the solar greenhouse ${ }^{[18]}$. To simplify the analysis, it can be gained that:

$$
Q_{d f r}=0.8 Q_{a}
$$

Combine Equations (4) and (5), it produces:

$$
\frac{T_{h}-T_{O}}{0.80 Q_{a}} A_{f r} t-\frac{\delta_{P O}}{\lambda_{P O}}=\frac{\delta_{\text {quilt }}}{\lambda_{\text {quilt }}}
$$

The released heat of the indoor air $Q_{a}$ can be described as:

$$
Q_{a}=C_{v} m \Delta T_{a}=C_{v} \rho \mathrm{V} \Delta T_{a}
$$

where, $C_{v}$ is the specific heat capacity of air; $m$ is the mass of the air in the solar greenhouse; $\Delta T_{a}$ is the difference of average indoor temperature corresponding to the time of the thermal insulation quilt is closing and next opening; $\rho$ is the density of air, which is $1.293 \mathrm{~kg} / \mathrm{m}^{3} ; V$ is the volume of air in the solar greenhouse, namely the indoor volume of solar greenhouse. In the present work, $\Delta T_{a}$ can be expressed by

$$
\Delta T_{a}=T_{h}-T_{l}
$$

At the range of $0^{\circ} \mathrm{C}-300^{\circ} \mathrm{C}$, the specific heat capacity of air, $C_{v}$ can be described as ${ }^{[19]}$ :

$$
C_{v}=1.0026+5.1000 \times 10^{-5} \mathrm{~T}-\hat{R}=0.71591+5.1000 \times 10^{-5} \mathrm{~T}
$$

where, $\hat{R}$ is the ideal gas constant, which is $8.314 \mathrm{~J} /\left(\mathrm{mol}^{\circ}{ }^{\circ} \mathrm{C}\right) ; T$ is the air temperature.

Considering during the period from thermal insulation quilt closing to the next opening, the average indoor temperature is usually at the range of $6^{\circ} \mathrm{C}-20^{\circ} \mathrm{C}$, the value of $C_{v}$ is varied from 0.7162 to $0.7169 \mathrm{~kJ} /\left(\mathrm{kg} \cdot{ }^{\circ} \mathrm{C}\right)$. And to simplify the analysis, take $C_{v}=0.7165 \mathrm{~kJ} /\left(\mathrm{kg} \cdot{ }^{\circ} \mathrm{C}\right)$. Substituting Equations (9)-(11) into Equation (8) gives:

$$
\frac{T_{h}-T_{O}}{0.80 Q_{a}} A_{f r} t-\frac{\delta_{P O}}{\lambda_{P O}}=\frac{T_{h}-T_{O}}{T_{h}-T_{l}} t \times \frac{1}{0.8 \rho C_{v}} \times \frac{A_{f r}}{V}-\frac{\delta_{P O}}{\lambda_{P O}}=\frac{\delta_{\text {quilt }}}{\lambda_{\text {quilt }}}
$$

In Equation (12), the ratio of thickness of PO film or thermal insulation quilt to its thermal conductivity is thermal resistance $R$, which is merely depended on the properties of themselves. The item of $\frac{T_{h}-T_{O}}{T_{h}-T_{l}} t$ is mainly depended on the indoor and outside temperature as well as the period from thermal insulation quilt closing to the next opening. The item of $\frac{1}{0.8 \rho C_{v}}$ is merely related to the air, and can be taken as constant $k$ for a very limited temperature range concerned in the present work. The ratio of front roof area $A_{f r}$ to indoor volume of the solar greenhouse $V$ depends on the structure of the solar greenhouse. And the present work defines $c_{1}=\frac{A_{f r}}{V}$ as solar greenhouse structural constant.

$$
\frac{T_{h}-T_{O}}{T_{h}-T_{l}} t \times k \times c_{1}-R_{P O}=R_{\text {quilt }}
$$

For a given type of solar greenhouse in a given area, the solar greenhouse structural constant $c_{1}$ is usually fixed. Moreover, under normal conditions, the period from thermal insulation quilt closing to the next opening is basically fixed, and the thermal resistance of $\mathrm{PO}$ film is also fixed. The lowest indoor temperature should be higher than that of the outdoor. As crop demand determines the lowest indoor temperature which can guarantee the growth of the crop, the allowable lowest indoor temperature, $T_{l}$ can be regarded as a fixed value for given crop. On the other hand, the drop of indoor temperature lags behind that of the outdoor temperature, especially for a given crop, it is usually necessary to adjust the daily average indoor temperature of the solar greenhouse to a relatively small range. Therefore, the indoor temperature $T_{h}$ can also be regarded as a fixed value at the time of the thermal insulation quilt begins to close. Lower outdoor temperature means higher ratio of $T_{h}-T_{o}$ to $T_{h}-T_{l}$, and thus thermal insulation quilt should have higher thermal resistance. Moreover, better thermal insulation of the envelopes suggests the higher of the lowest indoor temperature and the ratio of $T_{h}-T_{o}$ to $T_{h}-T_{l}$. As a result, thermal insulation quilt should have higher thermal resistance, namely thicker or with lower thermal conductivity.

Take the middle compartment with the width and length of $8 \mathrm{~m}$ and $8 \mathrm{~m}$ and planted with tomato as example. The thermal conductivity and thickness of PO film is $\lambda_{P O}=0.29 \mathrm{~W} /(\mathrm{m} \cdot \mathrm{K})$ and $\delta=0.1 \mathrm{~m}$, respectively. The allowable lowest indoor temperature for tomato is $8^{\circ} \mathrm{C}$, i.e. $T_{l}=8^{\circ} \mathrm{C}$. According to the structure and size of the solar greenhouse, it can be gain that the indoor volume $V=160.2 \mathrm{~m}^{3}$, the front roof area $A_{f r}=68 \mathrm{~m}^{2}$, and thus $c_{1}=0.424$. Assuming the indoor temperature $T_{h}=15^{\circ} \mathrm{C}$ at the time of the thermal insulation quilt begins to close and its close duration $t=$ $14 \mathrm{~h}$. In order to compare, assigned $c_{1}$ with different value, i.e. $0.30,0.35,0.40,0.45,0.50$. Figure 3 gives the thermal resistance of thermal insulation quilt under different outdoor temperature and solar greenhouse structural constant or the allowable lowest indoor temperature.

It can be seen that the lowest outdoor temperature has significant effect on the thermal resistance of thermal insulation quilt as discussed above. In the case of the allowable lowest indoor temperature keeps constant, higher solar greenhouse structural constant requires the thermal insulation quilt should have higher thermal resistance. In the case of the solar greenhouse structural constant is fixed, higher the allowable lowest indoor temperature requires the thermal insulation quilt should have higher thermal resistance. When the indoor volume of solar greenhouse keeps constant, higher solar greenhouse structural constant means has higher front roof area and thus higher thermal transfer area. As a result, in order to keep a higher indoor temperature, the thermal insulation quilt should have higher thermal resistance. Therefore, from the point of thermal insulation, it is necessary to reduce the solar greenhouse structural constant as much as possible in solar greenhouse design. In practice, when the width of solar greenhouse is fixed, lower solar greenhouse structural constant can be achieved by appropriately increasing the height of back wall 
while decreasing the slope of back roof as well as change the cross-section shape of gable.

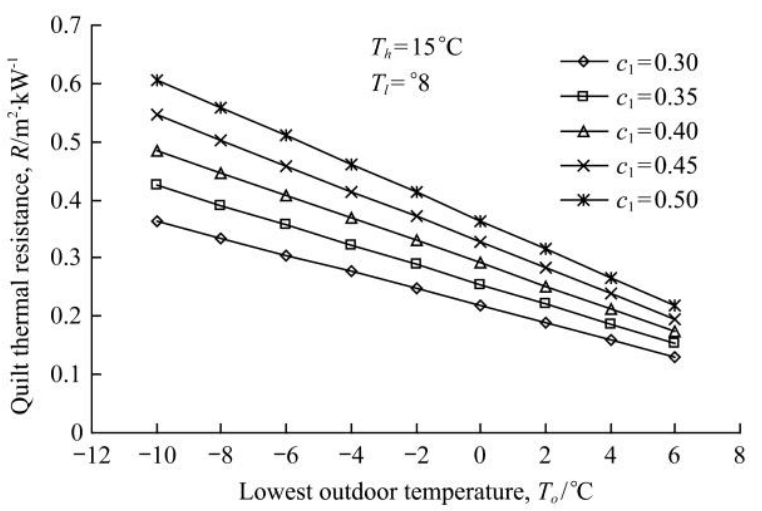

a.

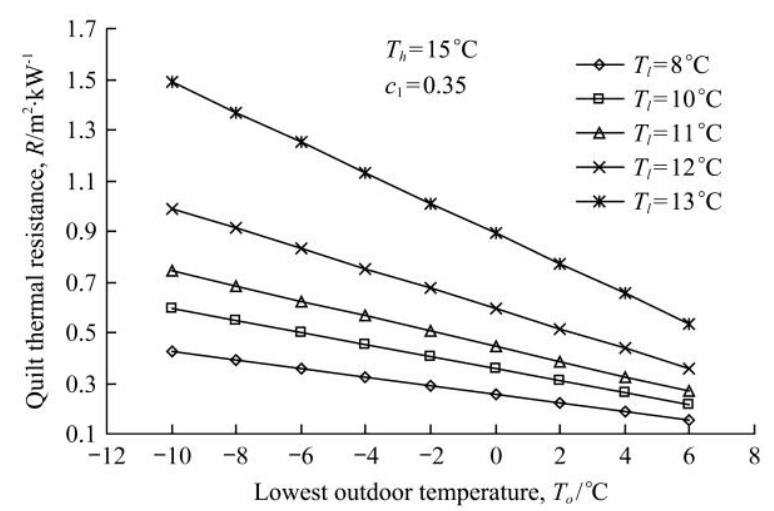

b.

Figure 3 Thermal resistance of thermal insulation quilt under different outdoor temperature with (a) greenhouse structural constant or (b) the allowable lowest indoor temperature

\section{Conclusions}

Different intrinsic thermal conductivity and thickness of the envelopes will lead to difference in the thermal flux and thus in the surface temperature of different envelopes. When the indoor temperature is the same and there are no thermal disfigurements, the heat flux through the envelope is different. And the temperature decreased in the order of front roof $>$ back roof $>$ back wall, indicating the front roof is the main channel of indoor heat loss. When there are thermal disfigurements in envelop, the increment of convective heat transfer coefficient and average heat flux, the drop of temperature of the wall are greater than those of the back roof and the front roof. Compared with the front roof and back roof, the wall is more sensitive to thermal disfigurements.

Under the assumption that the influence of thermal disfigurements on solar greenhouse temperature is monotonic linear, the allowable thermal disfigurements area fraction of front roof and back roof are given. Based on the analysis of heat transfer theory and the test results, comprehensive considering factors of the solar greenhouse structure, crop demand, outdoor lowest temperature, and thermal insulation quilt properties, the relationship of required thickness and thermal conductivity of thermal insulation quilt under different outdoor temperature and solar greenhouse structural constant or the allowable lowest indoor temperature is given.

\section{Acknowledgements}

This research was financially supported by Shaanxi Provincial Key Research and Development Program (Grant No. 2019TSLNY01-03), National Natural Science Foundation of China (31901420), Young Scientist Promotion Project of Jiangsu Science and Technology Association (2020-2-46).

\section{[References]}

[1] Sun Y C, Cao Y F, Wang H T, Zhou C J, Xiao J J, Jiang C Y, et al Influence of thermodynamic disfigurement on the convective heat transfer of solar greenhouse. Int J Agric \& Biol Eng, 2020; 13(4): 55-60.

[2] Ma C W, Wang P Z, Zhao S M, Chen J Y. Thermal insulation quilt materials and performance evaluation of solar greenhouse. Agriculture Engineering Technology, 2018; 38(31): 14-18. (in Chinese)

[3] Kim H K, Ryou Y S, Kim Y H, Lee T S, Kim Y H. Estimating the thermal properties of the cover and the floor in a plastic greenhouse. Energies, 2021; 14(7): 1970-1980.

[4] Sánchez-Guerrero M C, Medrano E, Olmo F D, Lorenzo P. Influence of a passive heating system that combines heat accumulators and thermal screen on the greenhouse microclimate. Acta Horticulturae, 2020; 1271(): 41-46.

[5] Subin M C, Karthikeyan R, Periasamy C, Sozharajan B. Verification of the greenhouse roof-covering-material selection using the finite element method. Materialstoday: Proceedings, 2020; 21(1): 357-366.

[6] Zhou C J, Zhou X Q, Gui J G. Performance analysis on several kinds of insulation pads for solar plastic greenhouse. Transactions of the CSAE, 1999; 15(2): 168-177. (in Chinese)

[7] Ma C W, Wang P Z, Zhao S M, Chen J Y. Thermal insulation quilt materials and performance evaluation of solar greenhouse. Agriculture Engineering Technology, 2018; 38(31): 14-18. (in Chinese)

[8] Jiang L Y, Zhang C H, Yu X Z, Ma Y, M C W. Test and analysis on the performance of heat preservation quilt for greenhouse. Journal of Chinese Agricultural Mechanization, 2017; 38(8): 64-67. (in Chinese)

[9] Zhang J K. Evaluation indices and system of thermal insulation quilt for solar greenhouse. Agriculture Machinery Quality and Supervision, 2008; 4: 30-32. (in Chinese)

[10] Liu C X, Ma C W, Wang P Z, Zhao S M, Cheng J Y, Wang M L. Analysis on affecting factors of heat preservation properties for thermal insulation covers. Transactions of the CSAE, 2015; 31(20): 186-193. (in Chinese)

[11] Liu C X, Ma C W, Wang P Z, Zhao S M, Cheng J Y, Wang M L. Theoretical analysis and experimental verification of heat transfer through thick covering materials of solar greenhouse. Transactions of the CSAE, 2015; 31(2): 170-176. (in Chinese)

[12] Xu D, Li Y, Zhang Y, Xu H, Liu X. Effects of orientation and structure on solar radiation interception in Chinese solar greenhouse. PLoS One, 2020; 15(11): e0242002.

[13] Sobota T. Fourier's law of heat conduction. Springer Netherlands, 2014

[14] Li Z, Xiong S, Sievers C, Hu Y, Fan Z, Wei N, Bao H, Chen S, Donadio D, Ala-Nissila T. Influence of Boundaries and Thermostatting on Nonequilibrium Molecular Dynamics Simulations of Heat Conduction in Solids. The Journal of Chemical Physics, 2019; 151: 234105.

[15] Bal H, Jannot Y, Gaye S, Demeurie F. Measurement and modelisation of the thermal conductivity of a wet composite porous medium: Laterite based bricks with millet waste additive. Construction \& Building Materials, 2013; 41: 586-593.

[16] Wardi F, Cherki A. B, Mounir S, Khabbazi A, Maaloufa Y. Thermal characterization of a new multilayer building material based on clay, cork and cement mortar. Energy Procedia, 2019; 157: 480-491.

[17] Modest M F. Radiation combined with conduction and convection. Radiative Heat Transfer. San Diego: Elsevire Science, 2003; pp. 680-727

[18] Chen D S, Zheng H S, Liu B Z. Comprehensive study on the meteorological environment of sunlighlt greenhouse. Transactions of the CSAE, 1990; 6(2): 77-81. (in Chinese)

[19] Liu H. A new linear relationship of average specific heat capacity and temperature of gas. Inner Mongolia Petrochemical Industry, 2013; 11: 13-15. (in Chinese) 